\title{
Primary nocturnal enuresis as a risk factor for sleep disorders: an observational questionnaire-based multicenter study
}

This article was published in the following Dove Press journal:

Neuropsychiatric Disease and Treatment

28 March 2013

Number of times this article has been viewed

\author{
Maria Esposito' \\ Beatrice Gallai \\ Lucia Parisi ${ }^{3}$ \\ Michele Roccella ${ }^{3}$ \\ Rosa Marotta ${ }^{4}$ \\ Serena Marianna Lavano 4 \\ Giovanni Mazzotta ${ }^{5}$ \\ Marco Carotenuto' \\ 'Center for Childhood Headache, \\ Clinic of Child and Adolescent \\ Neuropsychiatry, Department of \\ Mental Health, Physical and Preventive \\ Medicine, Second University of \\ Naples, Naples, Italy; ${ }^{2}$ Unit of Child \\ and Adolescent Neuropsychiatry, \\ University of Perugia, Perugia, Italy; \\ ${ }^{3}$ Child Neuropsychiatry, Department \\ of Psychology, University of \\ Palermo, Palermo, Italy; ${ }^{4}$ Department \\ of Psychiatry, "Magna Graecia" \\ University of Catanzaro, Catanzaro, \\ Italy; ${ }^{5}$ Unit of Child and Adolescent \\ Neuropsychiatry, AUSL Umbria 2, \\ Terni, Italy
}

Introduction: Primary nocturnal enuresis (PNE) is a common problem in developmental age with an estimated overall prevalence ranging from $1.6 \%$ to $15 \%$, and possible persistence during adolescence. There is a growing interest in the sleep habits of children affected by PNE, which is derived from the contradictory data present in clinical literature. The aim of the present study was to evaluate the presence of sleep disturbances in a population of children affected by PNE, and to identify whether PNE could be considered as a risk factor for sleep disturbances among children.

Materials and methods: A total of 190 PNE children (97 males, 93 females) aged 7-15 years, (mean $9.64 \pm 1.35$ years), and 766 typically developing children matched for age $(P=0.131)$ and gender $(P=0.963)$ were enrolled. To evaluate the presence of sleep habits and disturbances, all of the subjects' mothers filled out the Sleep Disturbances Scale for Children (SDSC), a questionnaire consisting of six subscales: Disorders in Initiating and Maintaining Sleep (DIMS), Sleep Breathing Disorders (SBD), Disorders of Arousal (DA), Sleep-Wake Transition Disorders (SWTD), Disorders of Excessive Somnolence (DOES), and Nocturnal Hyperhidrosis (SHY). The results were divided into "pathological" and "normal" scores using a cut-off value (pathological score $=$ at least three episodes per week), according to the validation criteria of the test. Then, the Chi-square test was used to calculate the statistical difference and a univariate logistic regression analysis was applied to determine the role of PNE as a risk factor for the development of each category of sleep disorders and to calculate the odds ratio (OR).

Results: PNE children show a higher prevalence of all sleep disturbances (41.03\% DIMS; 85.12\% SBD; 63.29\% DA; 67.53\% SWTD; 31.28\% DOES; 37.92\% SHY; 25.33\% SDSC total score), and according to OR results (SDSC total score OR $=8.293,95 \%$ confidence interval $[\mathrm{CI}]=5.079-13.540$; DIMS OR $=7.639,95 \% \mathrm{CI}=5.192-11.238 ; \mathrm{SBD}$ OR $=35.633$, $95 \% \mathrm{CI}=22.717-55.893 ; \mathrm{DA}$ OR $=13.734,95 \% \mathrm{CI}=9.476-19.906 ; \mathrm{SWTD}$ OR $=14.238$, $95 \% \mathrm{CI}=9.829-20.625$; DOES OR $=5.602,95 \% \mathrm{CI}=3.721-8.432$; $\mathrm{SHY}$ OR $=6.808,95 \%$ $\mathrm{CI}=4.608-10.059)$, PNE could be considered as a risk factor for the development of sleep disorders.

Conclusion: Among PNE children, sleep could be strongly altered, thus helping to affirm the hypothesis that PNE tends to alter sleep architecture, or it could itself be the consequence of an abnormal sleep structure. The findings also point to the existence of a potential increase in the risk of developing sleep disorders in the presence of PNE.

Keywords: primary nocturnal enuresis, SDSC, sleep

\section{Introduction}

According to the International Children's Continence Society criteria, ${ }^{1}$ nocturnal enuresis is defined as the involuntary loss of urine during the night in children over 5 years
Correspondence: Beatrice Galla

Neuropsychiatry, University of Perugia,

Via Enrico dal Pozzo, 06100 - Perugia

$\mathrm{Tel} / \mathrm{Fax}+39744204506$

Email beatrice.gallai@gmail.com 
of age, distinguished in a primary form (primary nocturnal enuresis [PNE]), and in a secondary form (secondary nocturnal enuresis). ${ }^{2}$ Moreover, nocturnal enuresis is divided into monosymptomatic nocturnal enuresis with no daytime urinary symptoms and nonmonosymptomatic nocturnal enuresis, if accompanied by daytime urinary symptoms. ${ }^{1}$

In general, nocturnal enuresis is a common problem during development, with an estimated overall prevalence ranging from $1.6 \%$ to $15 \%,{ }^{3-5}$ and possible persistence during adolescence. ${ }^{6}$ Bedwetting could be considered more common in boys, whereas daytime incontinence is prevalent in girls. ${ }^{7}$ The prevalence of nocturnal enuresis tends to decrease with age, supporting the traditional idea of maturational delay in voiding control, even if other mechanisms may be involved.

For years, PNE was interpreted as only resulting from unspecified psychological troubles, with no consideration for an interesting recent suggestion that PNE shares similarities with another very common symptom that occurs in developmental age - migraine without aura. ${ }^{8}$ In fact, enuresis and migraines could be linked by cortical system arousal dysfunction, vegetative hyperactivity, ${ }^{9-11}$ alteration in motor and visual coordination, ${ }^{12-14}$ and sleep disorders. ${ }^{15-17}$ As such, PNE and migraines could be interpreted as forms of familial stressors. ${ }^{18,19}$

From this perspective, PNE could be identified as a sort of "periodic syndrome," 20 such as growing pains, motion sickness, and others that share many of the same aspects as migraine, also considered their effects on learning abilities. ${ }^{21,22}$ In this light, the treatment should not exclude the causal role of both sleep disorders and abnormal behavior, ${ }^{23}$ while considering natural approaches such as sleep hygiene, ${ }^{24}$ nutraceuticals, ${ }^{25,26}$ and weight loss. ${ }^{27}$

On the other hand, there is a growing interest in the sleep habits of children affected by PNE, which is derived from the contradictory data present in the clinical literature. For example, in 2008 , Nevéus ${ }^{28}$ pinpointed the common parental report of deep sleep compared to controls, despite the low efficiency found in the quality of nighttime sleep as reported by children. Moreover, polysomnographic studies conducted among individuals affected by PNE are scarce or have been performed on small samples, with no conclusive data.

In 2009, Dhondt et $\mathrm{al}^{29}$ reported their polysomnographic findings of 29 subjects with refractory enuresis. The authors noted an increase in the periodic limb movement percentage and a sort of intrinsic hypnic instability, with a high threshold in cortical arousability, ${ }^{29}$ even if this alteration could be not identified as the unambiguous pathogenic mechanism.
The aim of the present study was to evaluate the presence of sleep disturbances in a population of children affected by PNE and to identify whether PNE could be considered as a risk factor for sleep disturbances among children.

\section{Materials and methods}

The study population consisted of 190 children (97 males, 93 females) aged $7-15$ years (mean $9.64 \pm 1.35$ years), who were consecutively referred from primary care pediatricians for PNE. The patients were referred to the following clinics between November 2011 to December 2012: the Center of Sleep Disorders for Developmental Age of Child and Adolescent Neuropsychiatry Clinic at the Second University of Naples; to the Unit of Child and Adolescent Neuropsychiatry of the Perugia University; to the Azienda Sanitaria Locale of Terni; and to the Department of Psychiatry of the University of Catanzaro.

The study population was compared with a group composed by 766 typically developing children (390 males, 376 females $)$ matched for age $(P=0.131)$ and gender $(P=0.963)$, who were recruited from the Campania, Umbria, and Calabria school regions.

All children affected by defined psychiatric illness (ie, schizophrenia, psychosis, attention deficit hyperactivity disorder), mental retardation (intelligence quotient $<75$ ), neurological diseases (ie, epilepsy, neuromuscular disorders, cerebral palsy), symptoms of lower urinary tract malfunction and/or infection, overweight (body mass index $[\mathrm{BMI}] \geq 85$ th percentile), or obesity (BMI $\geq 95$ th percentile) were excluded.

Data were collected from a pilot group (ten PNE, ten control children) and used to perform the sample size calculation. The desired power was set at 0.80 and error at 0.05 . The sample size was calculated using online software (http://www.dssresearch.com/toolkit/sscalc/size_a2.asp). The sample size required was found to be 13 subjects for each group, but there was the opportunity to recruit more patients (956 in total) in order to strengthen our findings.

\section{Sleep habits assessment}

To evaluate sleep habits and disturbances, all of the subjects' mothers filled out the Sleep Disturbances Scale for Children (SDSC) ${ }^{30}$ a standardized questionnaire for the assessment of sleep problems during development, consisting of 26 items grouped into six subscales: Disorders in Initiating and Maintaining Sleep (DIMS), Sleep Breathing Disorders (SBD), Disorders of Arousal (DA), Sleep-Wake Transition Disorders (SWTD), Disorders Of Excessive Somnolence (DOES), and Nocturnal Hyperhidrosis (SHY). Both the 
original or modified versions of this measure are widely used in school-aged children. ${ }^{31-35}$

According to the SDSC validation criteria, ${ }^{30}$ scores $\geq 71$ for the SDSC total score, $\geq 17$ for DIMS, $\geq 7$ for SBD, $\geq 6$ for DA, $\geq 14$ for SWTD, $\geq 13$ for DOES, and $\geq 7$ for SHY were considered as pathological.

The subjects in both groups were recruited from the same urban area; participants were Caucasian, and held a middleclass socioeconomic status.

All parents gave their written informed consent. The study was conducted according to the criteria of the Declaration of Helsinki. ${ }^{36}$

\section{Statistical analysis}

Mean differences in anthropometric (BMI z-score) and clinical characteristics between the PNE individuals and the control group were analyzed by $t$-test.

In order to evaluate the differences among both groups (PNE and controls) in terms of the prevalence of the pathological items of the SDSC, the results were divided into "pathological" and "normal" scores using a cut-off value (pathological score $=$ at least three episodes per week), according to the validation criteria of the test. Then, the Chi-square test was used to calculate the statistical difference.

The Bonferroni correction was applied, and $P$-values $<0.01$ were considered to be statistically significant. Moreover, an univariate logistic regression analysis was applied to determine the role of PNE as a risk factor for the development of each category of sleep disorders and to calculate the odds ratio (OR). The commercially available Statistica software (StatSoft Inc, Tulsa, OK, USA) was used for the statistical evaluation.

\section{Results}

Two study groups were matched for age $(P=0.131)$, gender $(P=0.963)$ and BMI z-score $(P=0.230)$, as shown in Table 1.

Table I Demographic and anthropometric characteristics of children affected by PNE and controls

\begin{tabular}{llll}
\hline & $\begin{array}{l}\text { PNE } \\
(\mathbf{n}=190)\end{array}$ & $\begin{array}{l}\text { Normal } \\
(\mathbf{n}=\mathbf{7 6 6})\end{array}$ & $\mathbf{P}$ \\
\hline Age & $9.64 \pm 1.35$ & $10.02 \pm 3.44$ & 0.131 \\
Sex ratio (M/F) & $97 / 93$ & $390 / 376$ & 0.963 \\
z-BMI & $0.63 \pm 0.38$ & $0.59 \pm 0.42$ & 0.230 \\
\hline
\end{tabular}

Notes: In order to verify the gender matching (M/F), the Chi-square test was applied; all other characteristics were evaluated by $t$-test analysis.

Abbreviations: PNE, primary nocturnal enuresis; $n$, number; $M$, male; $F$, female; z-BMI, z-score body mass index.
Table 2 shows the higher prevalence of pathological responses among children affected by PNE across 21 items when compared to control subjects, while the remaining four items (reluctance to go to sleep, presence of more than two awakenings per night, difficulty to go back to sleep, sleep apnea) do not differ significantly. Moreover, PNE individuals showed higher scores across the SDSC total $(P<0.001)$, DIMS $(P<0.001)$, SBD $(P<0.001)$, DA $(P<0.001)$, SWTD $(P<0.001)$, DOES $(P<0.001)$, and SHY $(P<0.001)$ scores than controls.

Finally, according to the results of the logistic regression analysis, PNE could be considered as a risk factor for developing sleep disorders according to the following results: SDSC total score $(\mathrm{OR}=8.293,95 \%$ confidence interval $[\mathrm{CI}]=5.079-13.540)$; DIMS $(\mathrm{OR}=7.639,95 \%$ $\mathrm{CI}=5.192-11.238) ; \mathrm{SBD}(\mathrm{OR}=35.633,95 \% \mathrm{CI}=22.717$ 55.893); $\mathrm{DA}(\mathrm{OR}=13.734,95 \% \mathrm{CI}=9.476-19.906)$; $\mathrm{SWTD}$ $(\mathrm{OR}=14.238,95 \% \mathrm{CI}=9.829-20.625) ; \mathrm{DOES}(\mathrm{OR}=5.602$, $95 \% \mathrm{CI}=3.721-8.432) ;$ and SHY $(\mathrm{OR}=6.808,95 \%$ $\mathrm{CI}=4.608-10.059)$ (Table 3$)$.

\section{Discussion}

In general, the acquisition of urinary continence seems to be complex and has probably not yet been completely understood. ${ }^{37}$ On the other hand, PNE could be considered one of the most common and disabling problems during development, yet it is still regarded as simple bedwetting, in spite of it being identified as a different condition, and presenting with various comorbidities such as neuromotor problems, ${ }^{38}$ attention difficulties, ${ }^{39}$ learning disabilities, and the possibility of being an epiphenomenon of other symptoms, or the effect of particular psychological states. ${ }^{40,41}$

Paradoxically, sleep disorders might be considered to be the most important comorbidity in enuretic children given the growing amount of evidence suggesting a significant relationship with particular anatomical patterns, ${ }^{42}$ obesity, ${ }^{43,44}$ breathing disorders during sleep, ${ }^{45-47}$ and various comorbidities, ${ }^{48}$ even if the relationship with other sleep disturbances has not yet been investigated. In this light, our findings tend to show that there is a higher prevalence of PNE children than typically developing children across all classes of sleep disturbances.

The pathogenesis of enuresis could be considered based on a mutual balance of three basic mechanisms: bladder capacity; nocturnal production of urine; and the threshold of arousability, ${ }^{49}$ all of which are elevated in the enuretic subject, ${ }^{50}$ as confirmed by the higher prevalence of DA and SWTD in our PNE sample (Table 3). 
Table 2 Different percentages of pathological items on the SDSC scales ( $\geq 3 /$ week) within the group of enuretic children who underwent the PSG study, with a starting population of enuretic children and a control group

\begin{tabular}{|c|c|c|c|c|}
\hline & $\begin{array}{l}\text { PNE } \\
(n=190) \\
(\%)\end{array}$ & $\begin{array}{l}\text { Control } \\
(n=766) \\
(\%)\end{array}$ & Chi-square values & $P^{a}$ \\
\hline I. Sleep less than 8 hours & 58.95 & 16.32 & 146.100 & $<0.001$ \\
\hline 2. Sleep latency $>30$ minutes & 33.16 & 6.53 & 101.040 & $<0.001$ \\
\hline 3. Reluctant to go to bed & 34.74 & 36.95 & 0.232 & NS \\
\hline 4. Difficulty getting to sleep at night & 40 & 16.45 & 49.265 & $<0.001$ \\
\hline 5. Anxiety when falling asleep & 61.58 & 7.7 & 290.618 & $<0.001$ \\
\hline 6. Hypnic jerks & 61.05 & 13.05 & 197.803 & $<0.001$ \\
\hline 7. Rhythmic movements while falling asleep & 36.84 & 8.62 & 97.100 & $<0.001$ \\
\hline 8. Vivid dream-like scenes while falling asleep & 35.79 & 5.09 & $|4| .263$ & $<0.001$ \\
\hline 9. Falling asleep sweating & 41.58 & 10.18 & 107.057 & $<0.001$ \\
\hline 10. More than two awakenings per night & 12.10 & 12.4 & 0.000 & NS \\
\hline II. Difficulty to fall asleep after awakenings & 8.42 & 12.66 & 2.237 & NS \\
\hline 12. Nocturnal hyperkinesis & 26.84 & 21.41 & 2.275 & NS \\
\hline 13. Sleep breathing difficulties & 68.95 & 12.4 & 266.527 & $<0.001$ \\
\hline 14. Sleep apnea & 6.32 & 6.01 & 0.000 & NS \\
\hline 15. Snoring & 54.74 & 17.23 & 113.168 & $<0.001$ \\
\hline 16. Night sweating & 64.74 & 13.19 & 222.644 & $<0.001$ \\
\hline 17. Sleepwalking & 22.11 & 6.66 & 39.626 & $<0.001$ \\
\hline 18. Sleep talking & 51.58 & 18.15 & 89.481 & $<0.001$ \\
\hline 19. Teeth grinding & 34.21 & 6.79 & 104.046 & $<0.001$ \\
\hline 20. Sleep terrors & 25.26 & 5.09 & 72.465 & $<0.001$ \\
\hline 21. Nightmares & 48.95 & 12.01 & $|30.73|$ & $<0.001$ \\
\hline 22. Difficulty in waking up in the morning & 41.05 & 32.38 & 4.721 & $<0.001$ \\
\hline 23. Awakes in the morning feeling tired & 45.26 & 27.94 & 20.426 & $<0.001$ \\
\hline 24. Sleep paralysis & 34.21 & 7.57 & 94.003 & $<0.001$ \\
\hline 25. Daytime somnolence & 27.89 & 9.4 & 44.207 & $<0.001$ \\
\hline 26. Sleep attacks & 15.79 & 3.13 & 43.143 & $<0.001$ \\
\hline Total SDSC & 16.32 & 2.35 & 58.224 & $<0.001$ \\
\hline
\end{tabular}

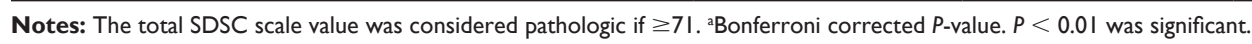

Abbreviations: SDSC, Sleep Disturbance Scale for Children; PSG, polysomnography; NS, not significant.

Table 3 The differences in the prevalence of pathological scores on the SDSC test between children affected by PNE and typically developing children (normal)

\begin{tabular}{|c|c|c|c|c|c|c|}
\hline & $\begin{array}{l}\text { PNE } \\
(n=190) \\
(\%)\end{array}$ & $\begin{array}{l}\text { Normal } \\
(n=766) \\
(\%)\end{array}$ & Chi-square & $P$ & OR & $95 \% \mathrm{Cl}$ \\
\hline $\begin{array}{l}\text { DIMS } \\
\text { pathological score }\end{array}$ & 41.03 & 8.29 & 126.121 & $<0.001$ & 7.639 & $5.192-11.238$ \\
\hline $\begin{array}{l}\text { SBD } \\
\text { pathological score }\end{array}$ & 85.12 & 13.94 & 379.169 & $<0.001$ & 35.633 & $22.717-55.893$ \\
\hline $\begin{array}{l}\text { DA } \\
\text { pathological score }\end{array}$ & 63.29 & 11.09 & 241.869 & $<0.001$ & 13.734 & $9.476-19.906$ \\
\hline $\begin{array}{l}\text { SWTD } \\
\text { pathological score }\end{array}$ & 67.53 & 12.63 & 250.131 & $<0.001$ & 14.238 & $9.829-20.625$ \\
\hline $\begin{array}{l}\text { DOES } \\
\text { pathological score }\end{array}$ & 31.28 & $7.4 I$ & 77.407 & $<0.001$ & 5.602 & $3.721-8.432$ \\
\hline $\begin{array}{l}\text { SHY } \\
\text { pathological score }\end{array}$ & 37.92 & 8.27 & 108.078 & $<0.001$ & 6.808 & $4.608-10.059$ \\
\hline $\begin{array}{l}\text { SDSC TOT } \\
\text { pathological score }\end{array}$ & 25.33 & 3.98 & 89.752 & $<0.001$ & 8.293 & $5.079-13.540$ \\
\hline
\end{tabular}

Abbreviations: SDSC, Sleep Disturbance Scale for Children; PNE, primary nocturnal enuresis; n, number; OR, odds ratio; Cl, confidence interval; DIMS, Disorders in Initiating and Maintaining Sleep; SBD, Sleep Breathing Disorders; DA, Disorders of Arousal; SWTD, Sleep-Wake Transition Disorders; DOES, Disorders Of Excessive Somnolence; SHY, Nocturnal Hyperhidrosis; NS, not significant. 
Bader et $\mathrm{al}^{51}$ showed that the sleep macrostructure of children affected by bedwetting could be considered as normal, even if characterized by the high presence of autonomic arousals before the voiding episodes, denying in this way the impairment in arousability. ${ }^{51}$ However, more recently, another sleep study was conducted on 35 enuretic subjects who were compared to 21 healthy controls. This study reintroduced the concept of dysregulation in the "bladder-brain dialogue," pinpointing the relationship between an overactive bladder and the ability to arouse the cortex, reporting differences in the sleep macrostructure of enuretic subjects, such as different representations of early stages of nonrapid-eye-movement sleep and a high rate of awakenings per hour. ${ }^{52}$

These findings tend to suggest the role of the arousal system in PNE pathogenesis; specifically, the small area around the locus coeruleus in the upper pons has been confirmed as playing a key role in PNE in some reports based on the activity of the autonomic nervous system. ${ }^{53,54}$ From this point of view, our results about the higher prevalence of all sleep disturbances in an enuretic sample (SDSC total score, $P \leq 0.001)$, particularly in SHY $(P \leq 0.001)$ and respiratory troubles during sleep (SBD, $P \leq 0.001$ ) could be interpreted as an epiphenomenon of autonomic nervous system activity. Conversely, it has been suggested that SRBD (particularly in the case of sleep apnea) may result in nocturnal diuresis mediated by atrial natriuretic peptide and antidiuretic hormone. ${ }^{46}$ In fact, conditions of negative intrathoracic pressure as a result of inspiratory effort posed against a closed airway may result in the release of atrial natriuretic peptide due to cardiac distension caused by the negative pressure environment. Consequently, this hormone could increase water excretion and inhibit both vasopressin and the renin-angiotensin-aldosterone complex, which are involved in fluid volume regulation. In this light, the higher rate of SRBD in enuretic children when compared to healthy controls could be explained, even when considering the exclusion of obese subjects in our study sample.

In addition, there is observational evidence to suggest that PNE has been found to occur after psychological stress or trauma, and that PNE results in increased psychological distress for the child: ${ }^{55-57}$ this suggests a putative role in the pathogenesis of DIMS, which was reported in our sample. Finally, Gozmen et al, ${ }^{58}$ in 2008, reported that children affected by enuresis tend to have a worse sleep quality when compared to unaffected children.

We should take into account some limitations of this study. Our data were derived from parental questionnaires and not from polysomnographic data and, therefore, the accuracy of our findings in evaluating sleep disturbances is limited. We could hypothesize that the parents of enuretic children could be used to checking their children during sleep in order to search for wetting episodes and to wake them more than parents' of typical developing children. In this way, we may speculate that parents of enuretic children may pay more attention to the children's sleep habits when compared to other parents.

In spite of these limitations, our study shows that among bedwetters, sleep could be strongly altered, thus affirming the hypothesis that PNE tends to alter the sleep architecture of affected children, or it could itself be the consequence of an abnormal sleep structure. In addition, the findings also pointed to the existence of a potential increase in the risk of developing sleep disorders in the presence of PNE, suggesting a new way to consider the relationship between sleep and enuresis in children.

\section{Disclosure}

The authors report no conflicts of interest in this work. None of the authors has any personal or financial support or involvement with organizations that hold financial interest in the subject matter.

\section{References}

1. Nevéus T, von Gontard A, Hoebeke P, et al. The standardization of terminology of lower urinary tract function in children and adolescents: report from the Standardisation Committee of the International Children's Continence Society. J Urol. 2006;176(1):314-324.

2. American Psychological Association. Diagnosis and Statistical Manual of Mental Disorders, 4th ed. Washington, DC: American Psychological Association; 2000:108-110.

3. Sakellaropoulou AV, Hatzistilianou MN, Emporiadou MN, et al. Association between primary nocturnal enuresis and habitual snoring in children with obstructive sleep apnoea-hypopnoea syndrome. Arch Med Sci. 2012;8(3):521-527.

4. Butler RJ, Golding J, Heron J; for ALSPAC Study Team. Nocturnal enuresis: a survey of parental coping strategies at $71 / 2$ years. Child Care Health Dev. 2005;31(6):659-667.

5. Caldwell PH, Edgar D, Hodson E, Craig JC. Bedwetting and toileting problems in children. Med J Aust. 2005;182(4):190-195.

6. Chiozza ML, Bernardinelli L, Caione P, et al. An Italian epidemiological multicentre study of nocturnal enuresis. Br J Urol. 1998; 81 Suppl 3:86-89.

7. Abrams P, Cardozo L, Khoury S, Wein A, editors. Incontinence. Paris, France: Health Publication, Ltd; 2002:513-551.

8. Carotenuto M, Esposito M, Pascotto A. Migraine and enuresis in children: An unusual correlation? Med Hypotheses. 2010;75(1): 120-122.

9. Yakinci C, Müngen B, Durmaz Y, Balbay D, Karabiber H. Autonomic nervous system functions in children with nocturnal enuresis. Brain Dev. 1997;19(7):485-487.

10. Dundaröz M, Denli M, Uzun M, et al. Analysis of heart rate variability in children with primary nocturnal enuresis. Int Urol Nephrol. 2001; 32(3):393-397. 
11. Yerdelen D, Acil T, Goksel B, Karatas M. Heart rate recovery in migraine and tension-type headache. Headache. 2008;48(2):221-225.

12. Touchette E, Petit D, Paquet J, Tremblay RE, Boivin M, Montplaisir JY. Bed-wetting and its association with developmental milestones in early childhood. Arch Pediatr Adolesc Med. 2005;159(12):1129-1134.

13. Bosson S, Holland PC, Barrow S. A visual motor psychological test as a predictor to treatment in nocturnal enuresis. Arch Dis Child. 2002;87(3):188-191.

14. Esposito M, Verrotti A, Gimigliano F, et al. Motor coordination impairment and migraine in children: a new comorbidity? Eur J Pediatr. 2012;171(11):1599-1604

15. Carotenuto M, Guidetti V, Ruju F, Galli F, Tagliente FR, Pascotto A. Headache disorders as risk factors for sleep disturbances in school aged children. J Headache Pain. 2005;6(4):268-270.

16. Vendrame M, Kaleyias J, Valencia I, Legido A, Kothare SV. Polysomnographic findings in children with headaches. Pediatr Neurol. 2008;39(1):6-11.

17. Bruni O, Miano S, Galli F, Verrillo E, Guidetti V. Sleep apnea in childhood migraine. J Headache Pain. 2000;1(3):169-172.

18. De Bruyne E, Van Hoecke E, Van Gompel K, et al. Problem behavior, parental stress and enuresis. J Urol. 2009;182(Suppl 4):2015-2020.

19. Esposito M, Gallai B, Parisi L, et al. Maternal stress and childhood migraine: a new perspective on management. Neuropsychiatr Dis Treat. 2013;2013(9):351-355.

20. Lin J, Rodrigues Masruha M, Prieto Peres MF, et al. Nocturnal enuresis antecedent is common in adolescents with migraine. Eur Neurol. 2012;67(6):354-359.

21. Esposito M, Pascotto A, Gallai B, et al. Can headache impair intellectual abilities in children? An observational study. Neuropsychiatr Dis Treat. 2012;8:509-513.

22. Esposito M, Carotenuto M, Roccella M. Primary nocturnal enuresis and learning disability. Minerva Pediatr. 2011;63(2):99-104.

23. Carotenuto M, Esposito M, Precenzano F, Castaldo L, Roccella M. Cosleeping in childhood migraine. Minerva Pediatr. 2011;63(2): 105-109.

24. Carotenuto M, Gallai B, Parisi L, Roccella M, Esposito M. Acupressure therapy for insomnia in adolescents: a polysomnographic study. Neuropsychiatr Dis Treat. 2013;9:157-162.

25. Esposito M, Ruberto M, Pascotto A, Carotenuto M. Nutraceutical preparations in childhood migraine prophylaxis: effects on headache outcomes including disability and behaviour. Neurol Sci. 2012;33(6): 1365-1368.

26. Esposito M, Carotenuto M. Ginkgolide B complex efficacy for brief prophylaxis of migraine in school-aged children: an open-label study. Neurol Sci. 2011;32(1):79-81.

27. Verrotti A, Agostinelli S, D'Egidio C, et al. Impact of a weight loss program on migraine in obese adolescents. Eur J Neurol. 2013;20(2): 394-397.

28. Nevéus T. Enuretic sleep: deep, disturbed or just wet? Pediatr Nephrol. 2008;23(8):1201-1202.

29. Dhondt K, Raes A, Hoebeke P, et al. Abnormal sleep architecture and refractory nocturnal enuresis. J Urol. 2009;182(Suppl 4): 1961-1965.

30. Bruni O, Ottaviano S, Guidetti V, et al. The Sleep Disturbance Scale for Children (SDSC). Construction and validation of an instrument to evaluate sleep disturbances in childhood and adolescence. J Sleep Res. 1996;5(4):251-261.

31. Bruni O, Ferini-Strambi L, Russo PM, et al. Sleep disturbances and teacher ratings of school achievement and temperament in children. Sleep Med. 2006;7(1):43-48.

32. Eitner S, Urschitz MS, Guenther A, et al. Sleep problems and daytime somnolence in a German population-based sample of snoring schoolaged children. J Sleep Res. 2007;16(1):96-101.

33. Esposito M, Roccella M, Parisi L, Gallai B, Carotenuto M. Hypersomnia in children affected by migraine without aura: a questionnaire-based case-control study. Neuropsychiatr Dis Treat. 2013;9:289-294.
34. Carotenuto M, Bruni O, Santoro N, Del Giudice EM, Perrone L, Pascotto A. Waist circumference predicts the occurrence of sleepdisordered breathing in obese children and adolescents: a questionnairebased study. Sleep Med. 2006;7(4):357-361.

35. Spruyt K, Cluydts R, Verleye GB. Pediatric sleep disorders: exploratory modulation of their relationships. Sleep. 2004;27(3):495-501.

36. World Medical Association (2008). World Medical Association Declaration of Helsinki: Ethical Principles for Medical Research Involving Human Subjects, Available at: http://www.wma.net/ en/30publications/10policies/b3/. Accessed February 16, 2013.

37. Naseri M, Hiradfar M. Monosymptomatic and non-monosymptomatic nocturnal enuresis: a clinical evaluation. Arch Iran Med. 2012;15(11): 702-706.

38. von Gontard A, Freitag CM, Seifen S, Pukrop R, Röhling D. Neuromotor development in nocturnal enuresis. Dev Med Child Neurol. 2006;48(9): 744-750.

39. Okur M, Ruzgar H, Erbey F, Kaya A. The evaluation of children with monosymptomatic nocturnal enuresis for attention deficit and hyperactivity disorder. Int J Psychiatry Clin Pract. 2012;16(3):229-232.

40. Coppola G, Costantini A, Gaita M, Saraulli D. Psychological correlates of enuresis: a case-control study on an Italian sample. Pediatr Nephrol. 2011;26(10):1829-1836.

41. Ellington EE, McGuinness TM. Mental health considerations in pediatric enuresis. J Psychosoc Nurs Ment Health Serv. 2012;50(4):40-45.

42. Carotenuto M, Esposito M, Pascotto A. Facial patterns and primary nocturnal enuresis in children. Sleep Breath. 2011;15(2):221-227.

43. Erdem E, Kogan BA, Feustel PJ. Relationship between body mass index and pediatric urologic diagnoses. J Pediatr Urol. 2007;3(4):268-272.

44. Alexopoulos EI, Kostadima E, Pagonari I, Zintzaras E, Gourgoulianis K, Kaditis AG. Association between primary nocturnal enuresis and habitual snoring in children. Urology. 2006;68(2):406-409.

45. Stone J, Malone PS, Atwill D, McGrigor V, Hill CM. Symptoms of sleep-disordered breathing in children with nocturnal enuresis. J Pediatr Urol. 2008;4(3):197-202.

46. Sans Capdevila O, Crabtree VM, Kheirandish-Gozal L, Gozal D. Increased morning brain natriuretic peptide levels in children with nocturnal enuresis and sleep-disordered breathing: a community-based study. Pediatrics. 2008;121(5):e1208-e1214.

47. Barone JG, Hanson C, DaJusta DG, Gioia K, England SJ, Schneider D. Nocturnal enuresis and overweight are associated with obstructive sleep apnea. Pediatrics. 2009;124(1):e53-e59.

48. Carotenuto M, Esposito M, Parisi L, et al. Depressive symptoms and childhood sleep apnea syndrome. Neuropsychiatr Dis Treat. 2012;8: 369-373.

49. Wolfish NM. Sleep/Arousal and enuresis subtypes. JUrol. 2001;166(6): 2444-2447.

50. Wolfish NM, Pivik RT, Busby KA. Elevated sleep arousal thresholds in enuretic boys: clinical implications. Acta Paediatr. 1997;86(4): 381-384.

51. Bader G, Nevéus T, Kruse S, Sillén U. Sleep of primary enuretic children and controls. Sleep. 2002;25(5):579-583.

52. Yeung CK, Diao M, Sreedhar B. Cortical arousal in children with severe enuresis. N Engl J Med. 2008;358(22):2414-2415.

53. Fujiwara J, Kimura S, Tsukayama H, et al. Evaluation of the autonomic nervous system function in children with primary monosymptomatic nocturnal enuresis - power spectrum analysis of heart rate variability using 24-hour Holter electrocardiograms. Scand J Urol Nephrol. 2001;35(5):350-356.

54. Unalacak M, Aydin M, Ermis B, et al. Assessment of cardiac autonomic regulation in children with monosymptomatic nocturnal enuresis by analysis of heart rate variability. Tohoku J Exp Med. 2004; 204(1):63-69.

55. Diaz Saldano D, Chaviano AH, Maizels M, et al. Office management of pediatric primary nocturnal enuresis: a comparison of physician advised and parent chosen alternative treatment outcomes. J Urol. 2007; 178(4 Pt 2):1758-1761; discussion 1762. 
56. Schober JM, Lipman R, Haltigan JD, Kuhn PJ. The impact of monosymptomatic nocturnal enuresis on attachment parameters. Scand J Urol Nephrol. 2004;38(1):47-52.

57. Dittmann RW, Wolter S. Primary nocturnal enuresis and desmopressin treatment: do psychosocial factors affect outcome? Eur Child Adolesc Psychiatry. 1996;5(2):101-109.
58. Gozmen S, Keskin S, Akil I. Enuresis nocturna and sleep quality. Pediatr Nephrol. 2008;23(8):1293-1296.

Neuropsychiatric Disease and Treatment

\section{Publish your work in this journal}

Neuropsychiatric Disease and Treatment is an international, peerreviewed journal of clinical therapeutics and pharmacology focusing on concise rapid reporting of clinical or pre-clinical studies on a range of neuropsychiatric and neurological disorders. This journa is indexed on PubMed Central, the 'PsycINFO' database and CAS.
The manuscript management system is completely online and includes a very quick and fair peer-review system, which is all easy to use. Visit http://www.dovepress.com/testimonials.php to read real quotes from published authors.

Submit your manuscript here: http://www.dovepress.com/neuropsychiatric-disease-and-treatment-journal 